\title{
The effect of spinal cord stimulation on idiopathic detrusor instability and incontinence: a case report
}

\author{
DJ READ, ${ }^{*}$ ED JAMES, C SHALDON \\ From the Royal Devon and Exeter Hospital, Exeter, UK
}

SUMMARY A patient with long-standing symptoms of detrusor instability has been treated by electrical stimulation of the spinal cord. Stimulation abolished all symptoms and unequivocally inhibited episodes of instability.

The effect of spinal cord stimulation in producing symptomatic improvement in a wide range of organic neurological diseases was first reported a decade ago.' The considerable benefits claimed in subsequent literature were almost entirely unsupported by any factual evidence,,$^{23}$ and this suggested a significant placebo element. Recent views ${ }^{4}$ of adequately assessed trials of spinal cord stimulation, largely in patients with multiple sclerosis, have identified urinary bladder dysfunction as the main beneficiary of such treatment, confirmed by the latest report in this field. ${ }^{\circ}$

Although a number of aspects of measured bladder function have been shown to be altered with spinal cord stimulation, as yet no directly stimulusassociated effect which can be correlated with simultaneous symptomatic change has been reported. We describe a patient with idiopathic bladder instability of 15 years' standing, unresponsive to all pharmacological, surgical and psychological therapeutic manoeuvres, in whom such a correlation was documented.

\section{Case history}

A 42-year-old female presented with a 15 year history of incontinence unaltered by urethroplasty performed elsewhere. At presentation, results of intravenous urography, cystoscopy, urine culture and neurological examination

*Present address and address for reprint requests: The Medical Unit, Severalls Hospital, Colchester, Essex.

Received 16 August 1984 and in final form 29 January 1985. Accepted 2 February 1985 were normal. Initial urodynamic studies showed that her incontinence was due to detrusor instability. Subsequent bladder training, anti-cholinergic drug therapy and Helmstein's distension failed to produce symptomatic improvement or any changes in the urodynamic parameters when assessed 5 months later.

By using air-filled balloon catheters, ${ }^{7}$ total bladder, rectal and, by subtraction, detrusor pressures were measured continuously, (1) as the bladder filled normally, and (2) by rapid filling per urethram. Recordings were obtained with the patient supine and ambulant. Urine losses were measured simultaneously using the electronic measuring nappy, ${ }^{89}$ and flow rates recorded during micturition. Prestimulation studies demonstrated detrusor spasms of, typically, $30 \mathrm{~cm}$ water lasting about 1 minute, producing symptoms of urgency and frank incontinence. No stress incontinence was detectable, micturition producing peak flows of $10-20 \mathrm{ml} \mathrm{s}^{-1}$ with varying amounts of residual urine. These findings were unaffected by the therapeutic manoeuvres mentioned.

Two platinum-tipped teflon-covered stainless steel electrodes (Ceramic Substrates and Components, Farnham Common, Buckinghamshire, UK) were inserted into the epidural space using the technique described by Illis et al, ${ }^{10}$ and the tips placed at vertebral levels D4 and D6. The spinal cord was continuously stimulated at $50 \mathrm{~Hz}$ with 400 $\mu \mathrm{S}$ unipolar pulses at a voltage of $2 \cdot 5-4 \mathrm{~V}$ by means of a RF coupled stimulator (modified Exeter incontinence control stimulator). ${ }^{112}$ With the stimulator switched $\mathrm{ON}$ no incontinence or instability up to a bladder volume of around 700 $\mathrm{ml}$ was detected. In contrast, repeat studies on subsequent days with the stimulator switched OFF showed instability and incontinence at bladder volumes of less than $500 \mathrm{ml}$.

Two subsequent provocative studies were conducted separated by approximately one week. On the first occasion, with the patient supine and stimulation initially switched OFF, the bladder was filled at $100 \mathrm{ml} \mathrm{min}^{-1}$ to approximately $350 \mathrm{ml}$, with no changes in the measured parameters. With the patient erect, a detrusor spasm 832 


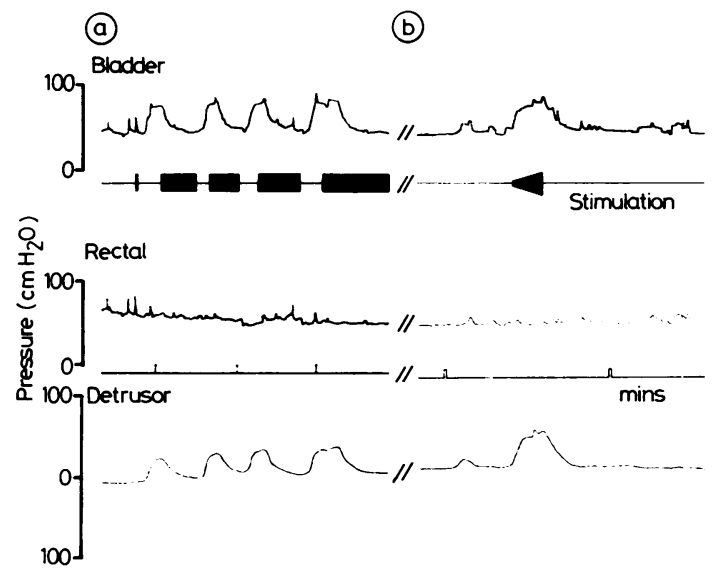

Fig With the stimulator switched $O N$, detrusor spasms are inhibited completely $(a)$ in the few seconds taken to adjust the voltage to the appropriate level (pulse repetition

frequency $50 \mathrm{~Hz}$, pulse width $400 \mu \mathrm{s})$; and (b) at the same voltage setting but only when the frequency initially set to 7 $\mathrm{Hz}$ is increased to at least $20 \mathrm{~Hz}$.

occurred almost immediately, with approximately $100 \mathrm{ml}$ of urine being leaked. At this point the stimulator was switched $O N$, inhibiting the spasm completely within the few seconds taken to adjust the voltage to the appropriate level. Switching OFF the stimulator was associated with the simultaneous reappearance of detrusor activity. These stimulation-related effects (fig a) were observed when this $\mathrm{ON}-\mathrm{OFF}$ procedure was repeated on 10 successive occasions within a one-hour period. In all instances, spasms coincided with urgency and varying degrees of incontinence. This sequence was repeated at an interval of one week with identical results.

On a separate occasion the pulse repetition frequency of the stimulator was reduced to $7 \mathrm{~Hz}$. At this lower frequency, stimulation did not inhibit the detrusor spasms, but, with the patient clearly demonstrating incontinence, the frequency was rapidly increased, a well-defined sharp cut-off of the observed stream and a corresponding abolition of detrusor activity coinciding with a frequency of about $20 \mathrm{~Hz}$ (fig b).

\section{Discussion}

The undoubted effect on the urinary bladder is probably the only feature which rescues spinal cord stimulation for chronic neurological disease from categorisation as an expensive electronic placebo. ${ }^{5}$ Measurements of the changes so far have shown only effects which take hours or days to become apparent ${ }^{13}$ and may very well be indirect in nature, though these effects have only been described in patients with bladder dysfunction due to multiple sclerosis. Thomas et al ${ }^{14}$ have drawn attention to the association of bladder instability with previously unrecognised and often asymptomatic minimal pyramidal dysfunction, suggesting a possible covert neurological cause for bladder instability in those patients in whom evidence of neurological disease is lacking. In addition, the idiopathic unstable bladder behaves unrodynamically, at least in the filling phase, in a similar fashion to that commonly found in patients with multiple sclerosis ${ }^{15}$ and for these reasons, on a purely pragmatic basis, it was decided to try cord stimulation in a patient with very longstanding troublesome symptoms, persistent detrusor instability documented urodynamically, in whom all conventional treatments had failed and for whom the choice lay between a permanent indwelling catheter or urinary diversion.

Her improvement, both symptomatically and on objective assessment, was impressive, providing an opportunity to record what is believed to be the first documentation of a measurable physiological response, coupled with a symptomatic change, simultaneously associated with cord stimulation. The sequential simultaneous decreases in detrusor contraction and abolition of the desire to void only when the cord was stimulated and the reappearance of uninhibited spasms in the absence of stimulation must be strong evidence in favour of the view that spinal cord stimulation can produce direct, genuine and reproducible beneficial effects not due to a placebo response. Because of the invariable association of cord stimulation with lower limb sensory phenomena, it is not possible to repeat the experiment in "a blind fashion" without active stimulation. ${ }^{5}$ Rapid conscious willed inhibition of previously intractable bladder detrusor spasms is not, however, generally regarded as likely and furthermore in this patient at least, such alterations appear to be reproducibly frequency dependent; a manoeuvre not associated with detectable alteration in accompanying lower limb sensation.

The observations made are sufficienty encouraging to justify a further investigation into the effects of spinal cord stimulation on detrusor instability and its associated symptoms, although we would stress that at present, these effects have only been demonstated in our patient in the short term. Clinical benefit was, however, maintained until subsequent electrode slippage (at seven months), following which no further attempt was made at replacement. Clearly long term observations must be made before any therapeutic benefit can be justifiably claimed.

\section{References}

${ }^{1}$ Cook AW, Weinstein SP. Chronic dorsal column stimulation in multiple sclerosis. NY State J Med 
1973;73:2868-72.

${ }^{2}$ Proceedings of the 6 th international symposium on external control of human extremities. Belgrade: Yugoslav Committee for Electronics and Automation 1978.

${ }^{3}$ Proceedings of the 3 rd international meeting on spinal cord stimulation 1980. Applied Neurophysiology $1981 ; 44$.

${ }^{4}$ Illis LS, Read DJ, Sedgwick AM, Tallis RC. Spinal cord stimulation in the UK. J Neurol Neurosurg Psychiatry 1983;46:299-304.

5 Read DJ, Matthews WB. What does spinal cord stimulation offer the multiple sclerosis patient? In: Warlow C, Garfield J, eds. Dilemmas in the Management of the Neurological Patient. Churchill Livingstone 1983.

- Hawkes CH, Beard R, Fawcett D, Paul EA, Thomas DGT. Dorsal column stimulation in multiple sclerosis: effects on bladder and long term findings. $\mathrm{Br}$ Med J 1983;287: 793-5.

7 James D. Continuous monitoring. In: Turner-Warwick $\mathrm{R}$, Whiteside CG, eds. The Urologic Clinics of North America. Philadelphia: WB Saunders Company, 1979;6:125-35.

8 James ED, Flack FC, Caldwell KPS, Martin MR. Continuous measurement of urine loss and frequency in incontinent patients. $\mathrm{Br} J$ Urol 1971;43:233-7.

ฯ James ED, Flack FC, Caldwell KPS, Smith MJ. Urine loss in incontinent patients: how often, how much? Clin Med 1974;81:13-7.

${ }^{10}$ Illis LS, Sedgwick SM, Oygar AE, Sabbahi Awadalla MA. Dorsal column stimulation in the rehabilitation of patients with multiple sclerosis. Lancet 1976;1(2):1383-6.

1 James ED. Equipment and methods involved in the treatment of urinary incontinence by electrical stimulation. Med Biological Eng Comput 1968;6:595-602.

12 Caldwell KPS, Cook PJ, Flack FC, James ED. Stress incontinence in females: report on 31 cases treated by electrical implant. J Obstetrics and Gynaecology of the British Commonwealth 1968;75:777-80.

${ }^{13}$ Read DJ, Matthews WB, Higson RH. The effect of spinal cord stimulation on function in patients with multiple sclerosis. Brain 1980;103:803-33.

${ }_{14}$ Thomas DG, Davies-Jones GAB, Clarke SJ. Urinary incontinence and minimal pyramidal disease. $\mathrm{Br} J$ Urol 1980;52:460-2.

${ }^{15}$ Philp T, Read DJ, Higson RH. The urodynamic characteristics of multiple sclerosis. Br J Urol 1981;53: 672-5. 